\title{
Seasonal Climate Prediction and Predictability of Atmospheric Circulation
}

\author{
June-Yi Lee and Bin Wang \\ Department of Meteorology and International Pacific Research Center, \\ University of Hawaii, Honolulu, HI,
}

USA

\section{Introduction}

While the detailed evolution of weather events may not be predictable beyond the span of a few days to two weeks due to the chaotic internal dynamics of atmospheric motion (Lorenz 1965), the statistical behavior of weather, that is the time or space averages, may be predictable over timescales of a season or longer due to the interaction between the atmosphere and the slowly varying lower boundary including ocean and land surface properties (Shukla 1998; Wang et al. 2009). In the past few decades, climate scientists have made tremendous advances in understanding and modeling the variability and predictability of the climate system. As a result, prediction of seasonal-to-interannual climate variations and the associated uncertainties using multiple dynamical models has become operational (Palmer et al. 2004; NOAA Climate Test Bed 2006; Lee et al. 2009). This chapter reviews and discusses the current status of seasonal climate prediction for the upper-tropospheric atmospheric circulation over the Northern Hemisphere $(\mathrm{NH})$, in particular, using eight coupled, state-of-the art models that have participated in the AsiaPacific Economic Cooperation Climate Center/Climate Prediction and its Application to Society (APCC/CliPAS) (Wang et al. 2009; Lee et al. 2010) and ENSEMBLE-based predictions of climate changes and their impactS (ENSEMBLES) project (Weisheimer et al. 2009; Alessandri et al. 2011). This is an extension of work from Lee et al. (2011), which addressed prediction and predictability of the $\mathrm{NH}$ summer upper-tropospheric circulation.

The multi-model ensemble (MME) approach was designed to quantifying forecast uncertainties due to model formulation near the turn of this century (Krishnamurti et al. 1999, 2000; Doblas-Reyes et al. 2000; Shukla et al. 2000; Palmer et al. 2000). The idea behind the MME is that if the model parameterization schemes are independent of each other, the model errors associated with the model parameterization schemes may be random in nature; thus, an averaging may cancel out the model errors contained in individual models. In general, the MME prediction is superior to the predictions made by any single-model component for both two-tier systems (Krishnamurti et al. 1999, 2000; Palmer et al. 2000; Shukla et al. 2000; Barnston et al. 2003) and one-tier systems (Hagedorn et al. 2005, DoblasReyes et al. 2005). 
Climate forecast skill and predictability depend on the spatial location and season. Using 14 climate prediction models, Wang et al. (2009) showed that the one-month lead seasonal MME prediction is more (less) skillful in predicting wintertime atmospheric variability in the Pacific North America (East Asia) region compared to its summer counterpart. Jia et al. (2011) demonstrated that the current climate models have a season-dependent forecast skill regarding the dominant atmospheric circulation pattern in the $\mathrm{NH}$ extratropics. While the climate models have a significant skill for the leading atmospheric pattern and the associated time variation in MAM, JJA, and DJF, they have a difficulty in capturing the leading mode in SON.

The source of predictability of seasonal atmospheric anomalies over the $\mathrm{NH}$ extratropics is mainly attributable to teleconnection patterns, often linked to tropical boundary forcing. In boreal winter, the Pacific-North American (PNA) pattern and North Atlantic Oscillation (NAO) tend to significantly influence surface climate conditions and they explain a significant part of the interannual variance of the atmospheric anomalies over the NH extratropics (Wallace and Guztler 1981; Barnston and Livezey 1987; Trenberth et al. 1998; Hoerling et al. 2001). In boreal summer, the circumglobal teleconection (CGT) pattern is dominant over the NH extratropics (Ding and Wang 2005), acting as a significant source of climate variability and predictability over the region (Lee et al. 2011; Ding et al. 2011).

How to determine the signal variance (the predictable part of total variance) and predictability of atmospheric variability on seasonal time scale is still an open issue. According to the conventional signal-to-noise ratio approach determined by ensemble simulations of a stand-alone atmospheric model (Charney and Shukla 1981; Shukla 1998; Rowell 1998; Kang and Shukla 2006), the summertime atmospheric variability in the NH extratropics is less predictable than its winter counterpart and far less than that in the tropics. However, predictability obtained from the AGCM-alone approach is highly modeldependent. To better estimate predictability of seasonal-to-interannual climate variations, Wang et al. (2007) and Lee et al. (2011) suggested a "predictable mode analysis (PMA)" approach, which relies on identification of the predictable leading modes of the interannual variations in observations and retrospective MME forecast. The predictability is estimated by the fractional variance accounted for by the predictable leading modes. This chapter uses the PMA approach to estimate predictability of upper-level atmospheric circulation in each season in comparison with Mean Square Error Method suggested by Kumar et al. (2007).

Section 2 introduces the observational and prediction data and analysis methods used in this study. In Section 3, the current status of dynamical prediction of the seasonal atmospheric circulation is investigated using eight coupled models' hindcast data. Section 4 is devoted to estimate potential predictability for seasonal-mean atmospheric circulation anomalies. The summary is given in section 5 .

\section{Data and analysis method}

\subsection{Retrospective forecast data}

This study uses one-month lead seasonal hindcast products of eight fully coupled oceanland atmosphere models. Table 1 lists the acronyms of the institutions and models 
mentioned in the text. The eight coupled models are from CAWCR, NCEP, and GFDL in the CliPAS project (Lee et al. 2011) and CMCC-INGV, ECMWF, IFM-GEOMAR, MF, and UKMO in the ENSEMBLES project (Weisheimer et al. 2009). None of the coupled models has flux adjustments. A brief summary of the coupled models and their retrospective forecasts is presented in Table 2. For more models' descriptions, refer to Lee et al. (2011) for the three CliPAS models and Weisheimer et al. (2009) for the five ENSEMBLES models.

The common retrospective forecast period of the models covers the 25 years of 1981-2005. All models were integrated from around February 1 to at least May 31 for the boreal spring season (hereafter MAM), from around May 1 to at least August 31 for the boreal summer season (hereafter JJA), from around August 1 to at least November 30 for boreal fall season (hereafter SON), and from around November 1 to at least February 28 for boreal winter season (hereafter DJF). Each model has a different ensemble size (Table 2). The one-month lead MME prediction was made by simply averaging the eight coupled models' ensemble means.

\subsection{Validation data}

The observed data for validating models' performance are as follows. Data for 200-hPa zonal wind and 200-hPa GPH are from the NCEP/department of Energy (DOE) reanalysis II data (Kanamitsu et al. 2002). SST data is from the improved Extended Reconstructed Sea Surface Temperature Version 2 (ERSST V2) data (Smith and Reynolds 2004).

\begin{tabular}{|l|l|}
\hline Acronym & Full names \\
\hline AMIP & Atmospheric general circulation model intercomparison project \\
\hline APCC & Asia-Pacific Economic Cooperation Climate Center \\
\hline CAWCR & Centre for Australia Weather and Climate Research \\
\hline CFS & Climate Forecast System \\
\hline CliPAS & Climate Prediction and its Application to Society \\
\hline CMCC-INGV & Euro-Mediterranean Centre for Climate Change \\
\hline DEMETER & $\begin{array}{l}\text { Development of a European Multimodel Ensemble System for } \\
\text { Seasonal to Interannual Prediction }\end{array}$ \\
\hline ECMWF & European Centre for Medium-Range Weather Forecast \\
\hline ENSEMBLES & ENSEMBLE-based predictions of climate changes and their impactS \\
\hline IFM-GEOMAR & Leibniz Institute of Marine Sciences at Kiel University \\
\hline GFDL & Geophysical Fluid Dynamic Lab \\
\hline MF & Météo France \\
\hline NCEP & National Center for Environmental Prediction \\
\hline POAMA & Predictive Ocean Atmosphere Model for Australia \\
\hline UKMO & UK Met Office \\
\hline
\end{tabular}

Table 1. Acronym names of institutions and models used in the text. 


\begin{tabular}{|c|c|c|c|c|c|}
\hline Institute & $\begin{array}{l}\text { Model } \\
\text { Name }\end{array}$ & AGCM & OGCM & $\begin{array}{l}\text { Ensemble } \\
\text { member }\end{array}$ & Reference \\
\hline CAWCR & POAMA1.5 & $\begin{array}{l}\text { BAM 3.0d } \\
\text { T47 L17 }\end{array}$ & $\begin{array}{c}\text { ACOM3 } \\
0.5-1.5^{\circ} \text { lat x } 2.0^{\circ} \\
\text { lon L31 } \\
\end{array}$ & 10 & Zhong et al (2005) \\
\hline GFDL & CM2.1 & $\begin{array}{c}\text { AM2.1 } \\
\text { 2olat x 2.5olon } \\
\text { L24 }\end{array}$ & $\begin{array}{c}\text { MOM4 } \\
\text { 1/3olat x 1olon L50 }\end{array}$ & 10 & $\begin{array}{l}\text { Delworth et al } \\
\text { (2006) }\end{array}$ \\
\hline NCEP & CFS & $\begin{array}{c}\text { GFS } \\
\text { T62 L64 }\end{array}$ & $\begin{array}{c}\text { MOM3 } \\
\text { 1/3olat x 5/8olon } \\
\text { L27 }\end{array}$ & 15 & Saha et al (2006) \\
\hline $\begin{array}{l}\text { CMCC- } \\
\text { INGV }\end{array}$ & CMCC & $\begin{array}{l}\text { ECHAM5 } \\
\text { T63 L19 }\end{array}$ & $\begin{array}{c}\text { OPA } 8.2 \\
2.0^{\circ} \times 2.0^{\circ} \mathrm{L} 31\end{array}$ & 9 & $\begin{array}{c}\text { Alessandri et al } \\
\text { (2011) } \\
\text { Pietro and Masina } \\
(2009)\end{array}$ \\
\hline ECMWF & ECMWF & $\begin{array}{l}\text { IFS CY31R1 } \\
\text { T159 L62 }\end{array}$ & $\begin{array}{c}\text { HOPE-E } \\
1.4^{\circ} \times 0.3^{\circ}-1.4^{\circ} \text { L29 }\end{array}$ & 9 & $\begin{array}{c}\text { Stockdale et al. } \\
(2011) \\
\text { Balmaseda et al. } \\
(2008)\end{array}$ \\
\hline $\begin{array}{l}\text { IFM- } \\
\text { GEOMAR }\end{array}$ & IFM & $\begin{array}{l}\text { ECHAM4 } \\
\text { T42 L19 }\end{array}$ & $\begin{array}{c}\text { OPA } 8.2 \\
2.0^{\circ} \text { lat } \times 2.0^{\circ} \text { lon } \\
\text { L31 }\end{array}$ & 9 & $\begin{array}{c}\text { Keenlyside et al. } \\
\text { (2005) } \\
\text { Jungclaus et al. } \\
\text { (2006) }\end{array}$ \\
\hline MF & MF & $\begin{array}{c}\text { IFS } \\
\text { T95 L40 }\end{array}$ & \begin{tabular}{|c|} 
OPA 8.0 \\
182GPx152GP L31
\end{tabular} & 9 & $\begin{array}{l}\text { Daget et al. (2009) } \\
\text { Salas Melia (2002) } \\
\end{array}$ \\
\hline UKMO & UKMO & $\begin{array}{l}\text { ECHAM5 } \\
\text { T42 L19 }\end{array}$ & \begin{tabular}{|c|} 
MPI-OM1 \\
2.5o lat $x 0.5^{\circ}-2.5^{\circ}$ \\
lon L23
\end{tabular} & 9 & $\begin{array}{l}\text { Collins et al. } \\
\qquad(2008)\end{array}$ \\
\hline
\end{tabular}

Table 2. Description of the coupled models and their retrospective forecast used in this study.

\subsection{Forecast quality measures}

The measure of prediction skill includes the temporal correlation coefficient (TCC) skill, evaluating the interannual variability, and anomaly pattern correlation coefficient (PCC) skill for spatial similarity. We also calculated the area-averaged TCC skill over the $\mathrm{NH}$ tropics $\left(\mathrm{Eq}-30^{\circ} \mathrm{N}\right)$ and extratropics $\left(30^{\circ}-80^{\circ} \mathrm{N}\right)$, respectively, taking latitudinal weight into account.

We define a skill score as representing the coupled models' capability in predicting empirical orthogonal function (EOF) modes in terms of the PCC score for eigenvector and TCC score for the principal component (PC) time series for each mode. The skill score for each mode $(i)$ is calculated by

$$
\text { Skill Score }(i)=\sqrt{\operatorname{PCC}(i) \times \operatorname{TCC}(i)} .
$$


The skill score ranges from 0 (no skill at all) to 1 (for perfect forecast). It should be mentioned that we reordered the EOF modes of the MME prediction according to the skill score because the order of the predicted EOF mode is not necessarily the same as its observed counterpart. In order to reorder the predicted EOF modes, the skill score for the first observed mode was calculated against all of the predicted modes and then the predicted mode that had the best skill score with the first observed mode was taken as the first predicted mode. Repeating the above process, other predicted modes were similarly determined. In the case of $200-\mathrm{hPa}$ geopotential height (Z200) in all season, there was no change of mode order until the $3^{\text {rd }}$ predicted mode.

\section{Dynamical prediction of seasonal-mean atmospheric circulation}

\subsection{Variance}

The upper tropospheric circulation is represented by geopotential height at 200-hPa (Z200 hereafter). Figure 1 compares the observed and hindcast interannual variance of the upperlevel circulation along with the climatological jet stream in each season. Individual ensemble hindcasts of each model are used to estimate standard deviation of the Z200 anomalies for individual models in each season. The composite of individual models' total standard deviation is used for the MME. Note that the MME is able to capture the location of jet streams in both hemispheres and the atmospheric variability centers over the Tropics in all seasons. However, it has difficulty in capturing the observed variability centers particularly over the NH extratropics, except over the PNA region for most seasons. Models tend to overestimate the tropical variability and underestimate the high latitude variability.

\subsection{Season-dependence}

Season-dependent MME forecast skills are investigated for the period 1981-2005. Figure 2 shows the TCC skill of one-month lead MME predictions for Z200 in each season. The skillful forecast for Z200 is primarily confined in the tropics (Fig. 2a) in all seasons that are consistent with earlier results (Peng et al. 2000). Nonetheless, the MME has significant skills over some specific geographical locations in the $\mathrm{NH}$ extratropics depending on season, suggesting that predictable patterns (or modes) of the seasonal upper-level circulation in the region may exist. For example, atmospheric variability over the PNA region is more predictable during MAM and DJF while that over the Asian region is more predictable during JJA and SON.

In the tropics, the area-averaged TCC skill is the lowest in JJA and SON. On the other hand, in the entire $\mathrm{NH}$ extratropics $\left(0-360^{\circ} \mathrm{E}, 30-80^{\circ} \mathrm{N}\right)$ TCC is the highest in JJA, although over the PNA region it is higher in DJF than in JJA. The TCC skill over the Southern Hemisphere (SH) shows a season-dependent pattern as well. The skill tends to increase in southern hemisphere subtropics and midlatitude during DJF and SON. The South Pacific convergence region tends to have higher skill than other southern hemisphere regions.

We also investigate the TCC skill for 500-hPa geopotential height (Z500) which is often used for representing mid-tropospheric atmospheric circulation. Comparison between Fig. 2 and 3 indicates that Z200 is more predictable than Z500 although the spatial pattern of the TCC for Z200 is very similar to that for Z500. 
(a) Observation
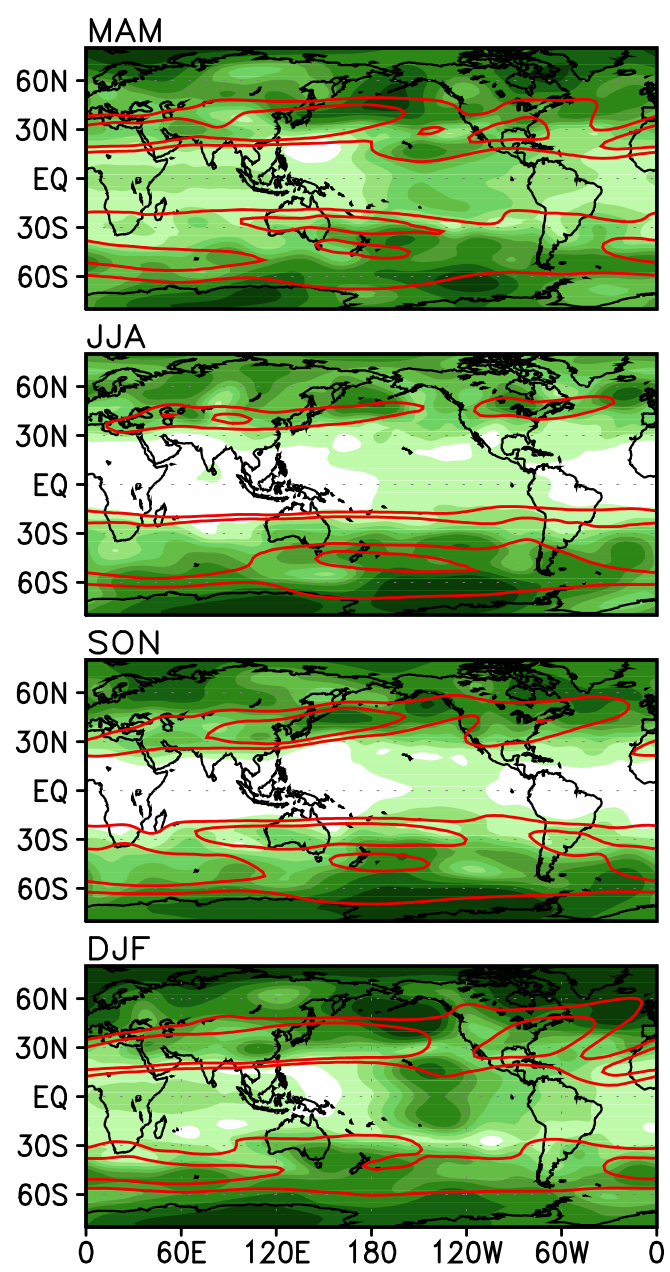

(b) $M M E$
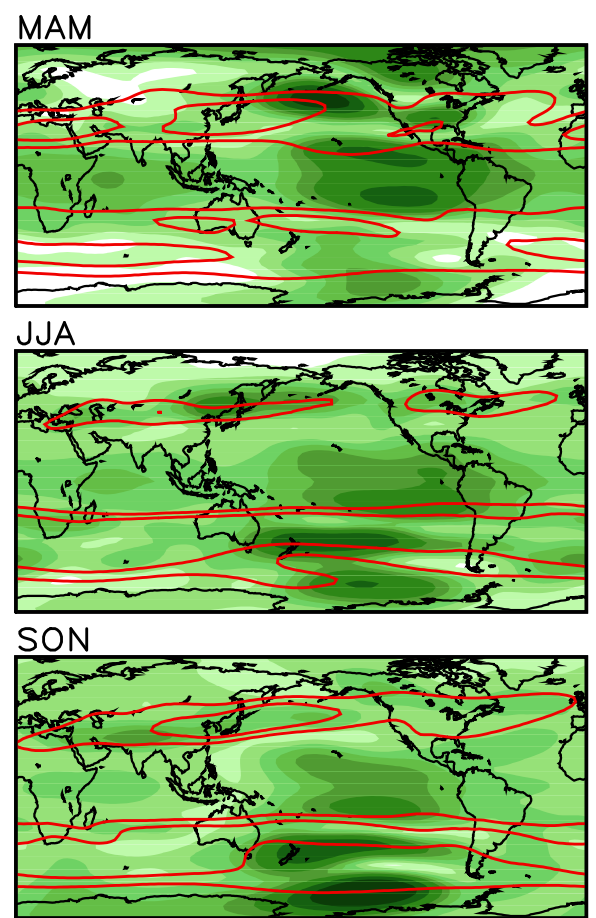

DJF

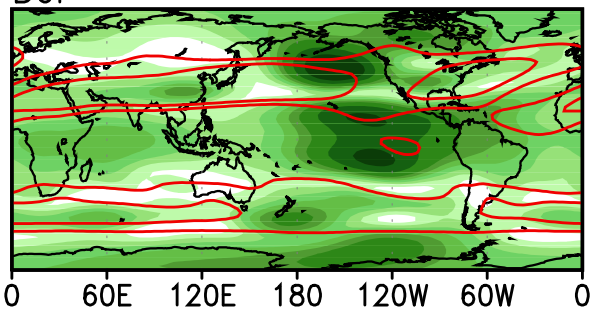

Fig. 1. Standard deviation of geopotential height (shading) anomalies and climatological mean of zonal wind (contour) at $200 \mathrm{hPa}$ in each season obtained from (a) observations and (b) the one-month lead MME seasonal prediction. The units are $m$ for geopotential height and $\mathrm{m} \mathrm{s}^{-1}$ for zonal wind. 20 and $30 \mathrm{~m} \mathrm{~s}^{-1}$ zonal wind are contoured. 


\section{Temporal Correlation Skill for Z200}

(a) MAM

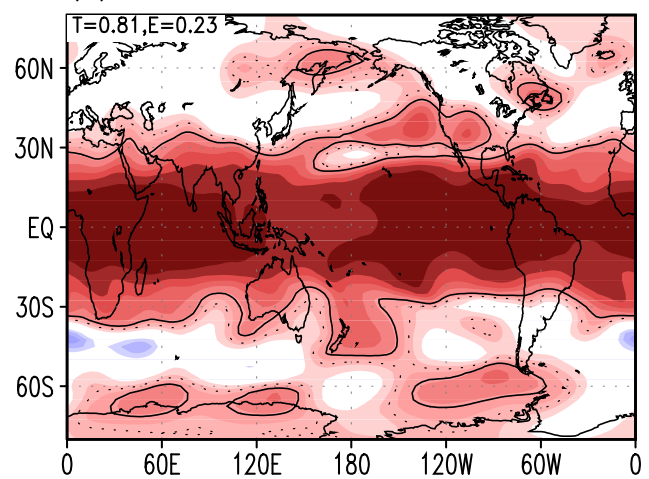

(b) JJA

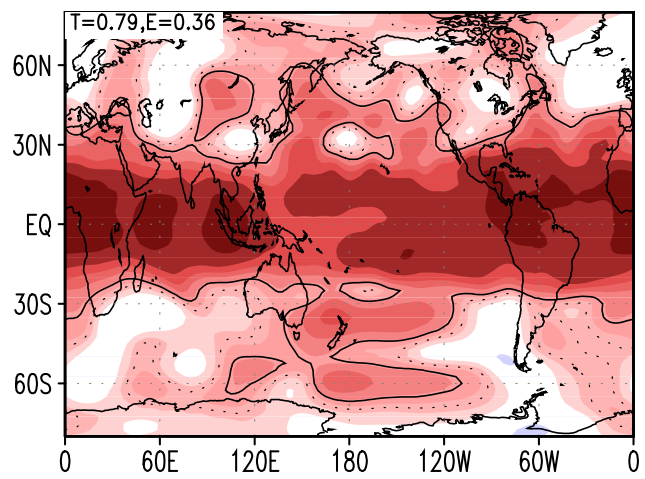

(c) SON

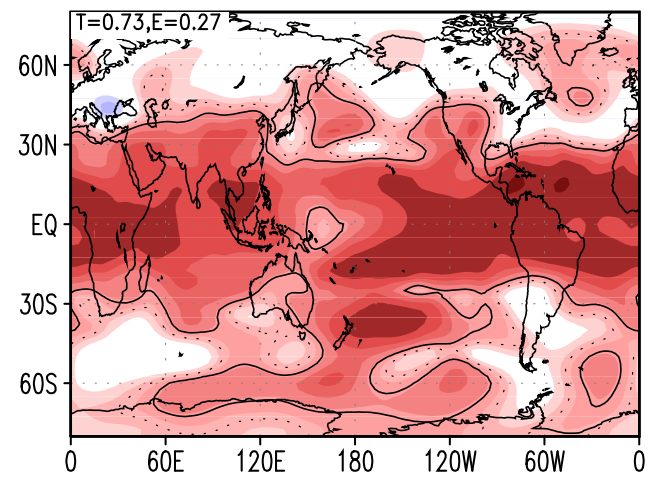

(d) DJF

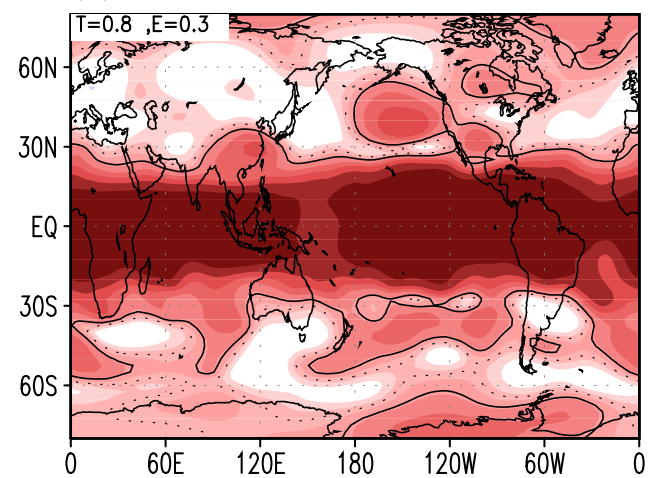

Fig. 2. The temporal correlation coefficient (TCC) skill for the one-month lead prediction of 200-hPa geopotential height (Z200) in (a) MAM, (b) JJA, (c) SON, and (d) DJF obtained from the eight coupled models' multi-model ensemble (MME) for the period of 1981-2005 in the Northern Hemisphere (NH). Solid (dashed) line represents statistical significance of the correlation coefficients at 95\% (99\%) confidence level. The numbers in the left upper corners indicate averaged correlation skill over the tropics (T: 0-360 $\left.\mathrm{E}, \mathrm{Eq}-30^{\circ} \mathrm{N}\right)$ and extratropics (E: $0-360^{\circ} \mathrm{E}, 30-80^{\circ} \mathrm{N}$ ) in the $\mathrm{NH}$. 
Temporal Correlation Skill for Z500
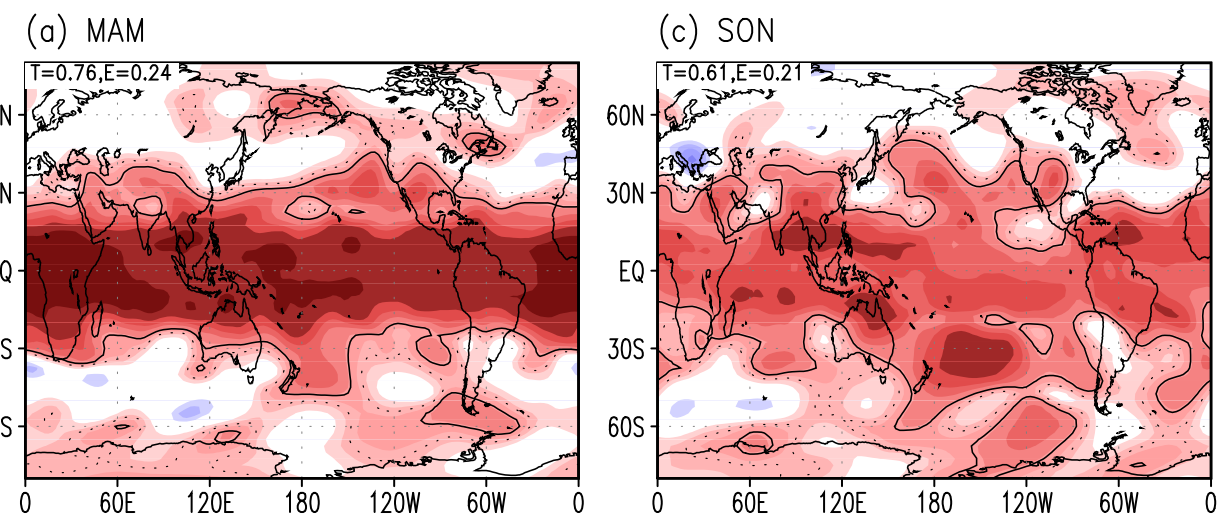

(b) JJA

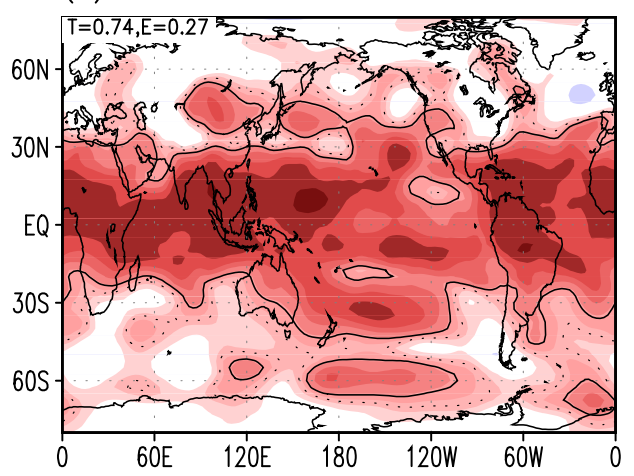

(d) DJF
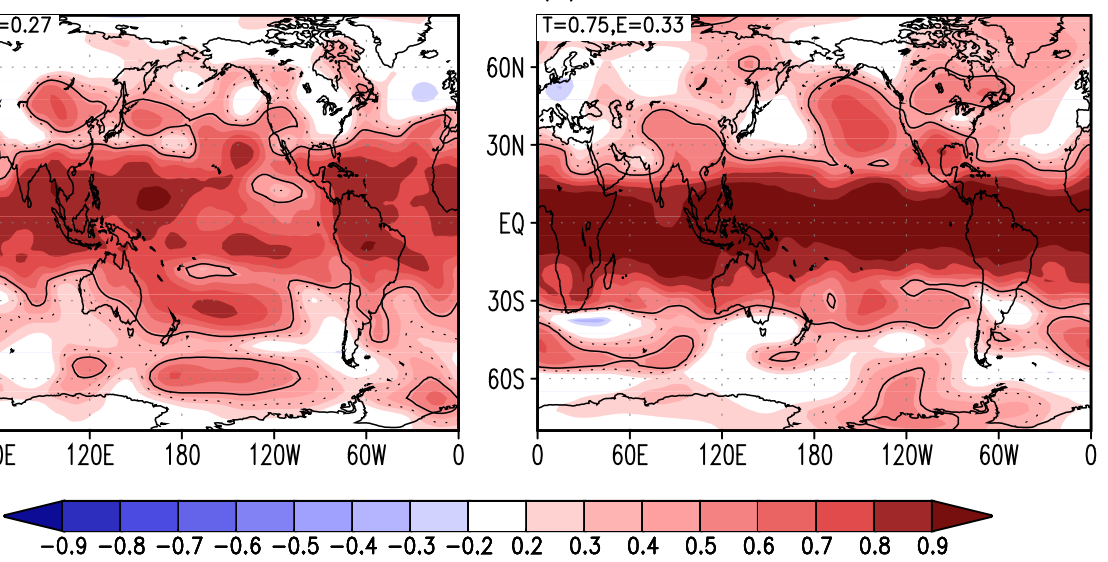

Fig. 3. Same as Fig. 2 except for 500-hPa geopotential height (Z500).

\subsection{Predictable modes}

It is important to understand the source of the prediction skill in the current coupled models and identify predictable modes of climate variability. To this end, we evaluate how well the MME hindcast captures the first two dominant modes of the Z200 variability in each season. To identify the major modes of upper-tropospheric atmospheric circulation, we first applied EOF analysis, using the correlation matrix, to the seasonal $\mathrm{Z} 200$ over the entire $\mathrm{NH}\left(0-360^{\circ} \mathrm{E}\right.$, $\mathrm{Eq}-80^{\circ}$ ) for observations and for the MME prediction. All data were interpolated to the same geographic grid to avoid the latitudinal weighting effect and data were normalized by their own standard deviation. 
Figures 4-7 show the first and second EOF modes of the NH Z200 variability for observations and the one-month lead MME prediction in each season. Similar to the major modes of JJA Z200 discussed in Lee et al. (2011), the first two EOF modes of the NH Z200 variability in other seasons are also understood in terms of ENSO teleconnection dynamics. For all seasonal cases, a strong positive (negative) phase in the first mode tends to occur simultaneously or after the mature phase of La Niña (El Niño), and is thus driven by prolonged impacts of the ENSO from the preceding SON to following JJA. The second mode, on the other hand, is regulated by the developing phase of the ENSO starting from the preceding DJF to following SON on the interannual time scale and is correlated with the SST anomalies over the North Pacific, North Atlantic, and tropical Western Pacific on the interdecadal time scale.

EOF 1

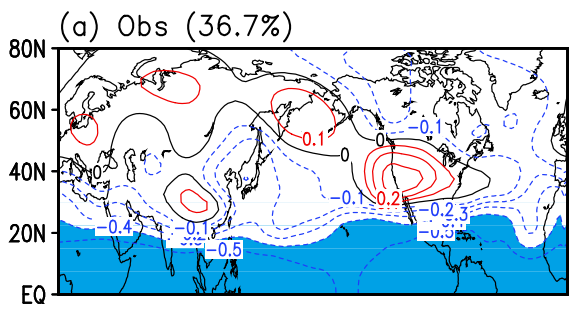

(b) MME (53.3\%)

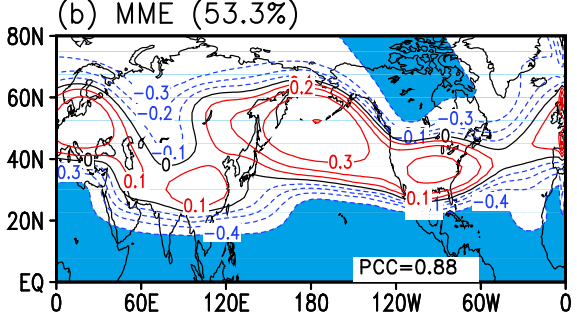

(c) PC

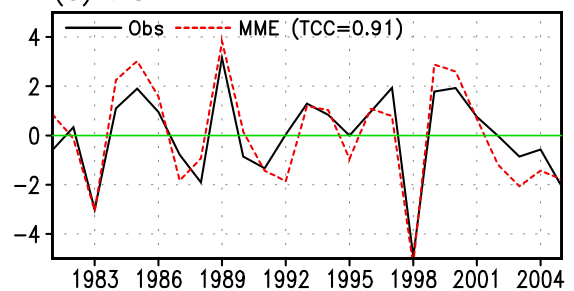

EOF2

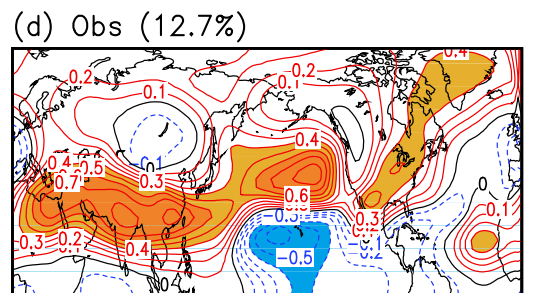

(e) $\operatorname{MME}(25.7 \%)$

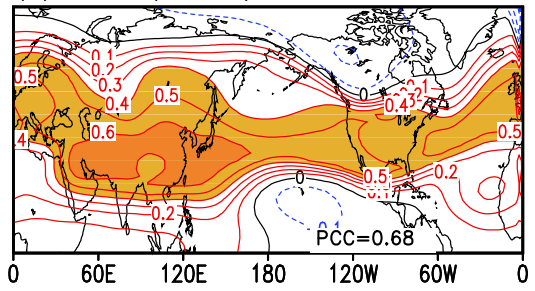

(f) $P C$

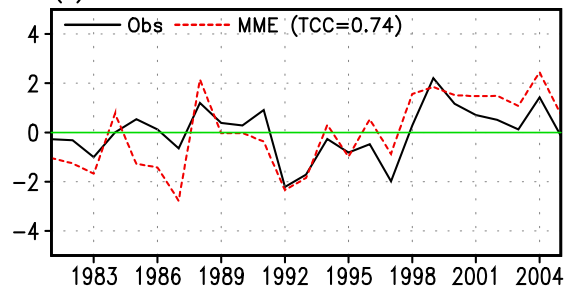

Fig. 4. Spatial patterns of the first (left panels) and second (right panels) eigenvectors of 200$\mathrm{hPa}$ GPH anomalies in MAM obtained from observation $(\mathrm{a}, \mathrm{d})$ and 8-coupled modes' MME prediction $(b, e)$, respectively. The numbers in the right lower corners in (d) and (e) indicate pattern correlation coefficient (PCC) between observation and the corresponding prediction. (c) and (f) principal components (PCs) of the first and the second EOF modes obtained from observation (black solid line) and MME (red dashed line). The numbers within the parenthesis in the figure legend in lower panels indicate the temporal correlation coefficients (TCC) between the observed and MME PC time series. 
EOF 1

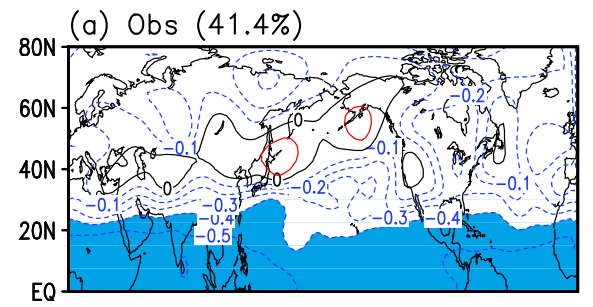

(b) $\operatorname{MME}(57.4 \%)$

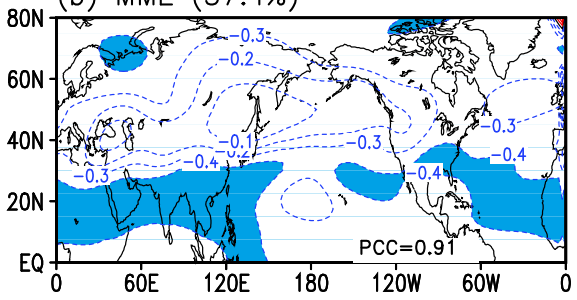

(c) PC

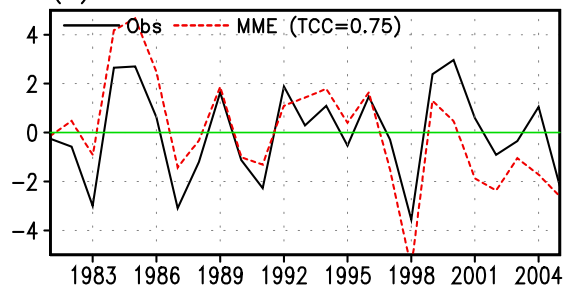

EOF2

(d) Obs (15.6\%)

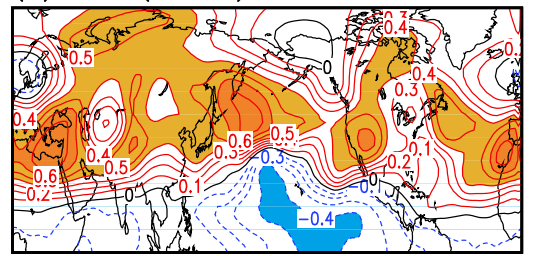

(e) $\operatorname{MME}(29.7 \%)$

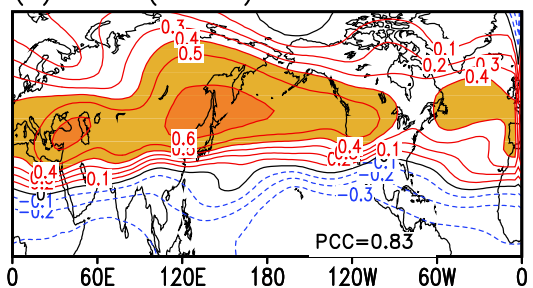

(f) $P C$

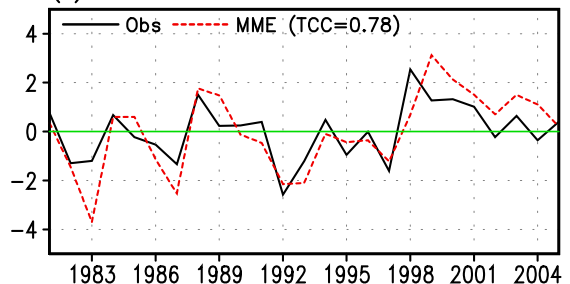

Fig. 5. Same as Fig. 4 except for JJA.

The predictability source of the first two modes can be more clearly depicted by the lead-lag correlation coefficients for seasonal SST against the first and second PC of Z200 shown Fig. 8. We just show the DJF case, since the other seasons have similar results. Figure 8 indicates that the first mode is associated with a typical or conventional eastern Pacific El Nino with complimentary same-sign SST anomalies occurring in Indian Ocean and Atlantic. On the other hand, the second mode seems to be associated with a central Pacific El Nino with pronounced opposite-sign SST anomalies in the western Pacific and Atlantic but little SST anomalies in the Indian Ocean. This suggest that the tropical precipitation anomalies associated with the locations of the tropical SST anomalies are critical important for determining the extratropical response.

The MME is capable of predicting the spatial and temporal structures of the two leading EOF modes one-month ahead with high fidelity in each season, except for the second EOF mode of DJF Z200. The MME's forecast skill for the EOF modes will be more discussed in section 4.2. 


\section{EOF 1}

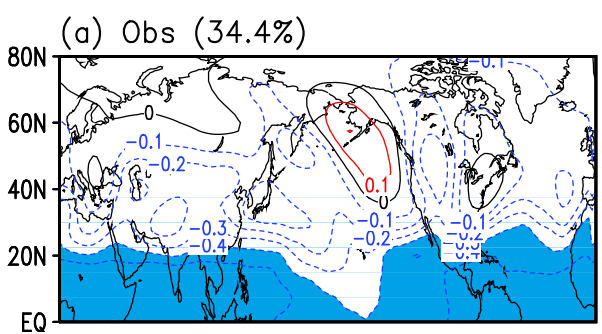

(b) MME (57.9\%)

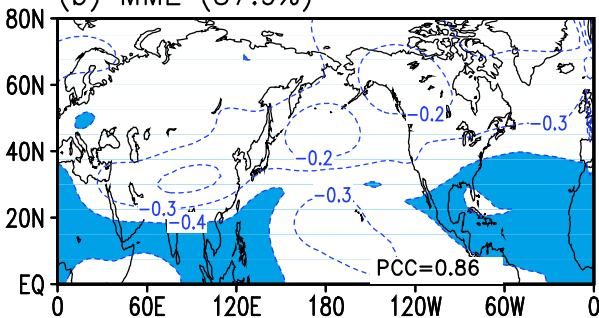

(c) $\mathrm{PC}$

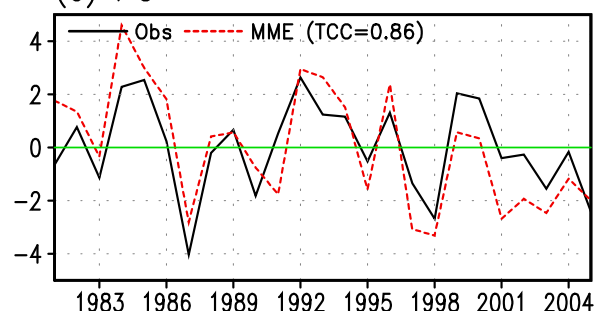

\section{EOF2}

(d) Obs (12.3\%)

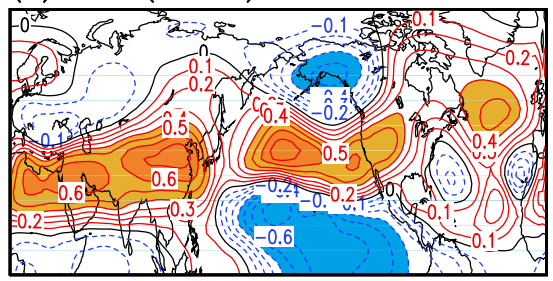

(e) MME (22.4\%)

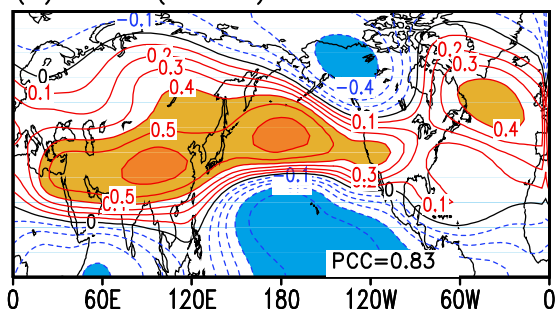

(f) $\mathrm{PC}$

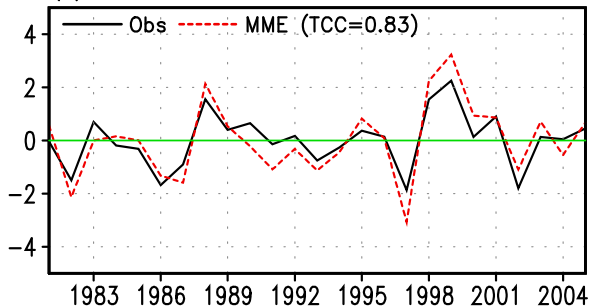

Fig. 6. Same as Fig. 4 except for SON. 
EOF 1
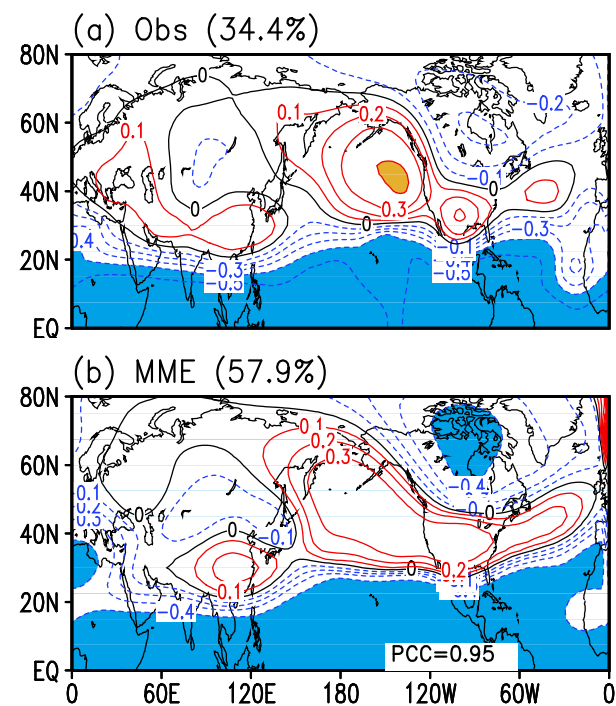

(c) PC

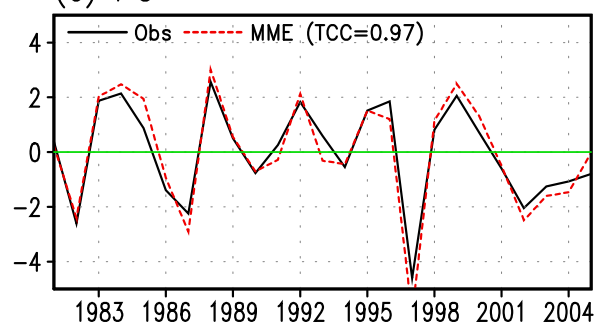

EOF2

(d) Obs (12.3\%)

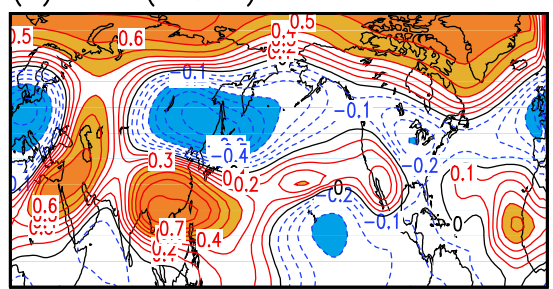

(e) MME (22.4\%)
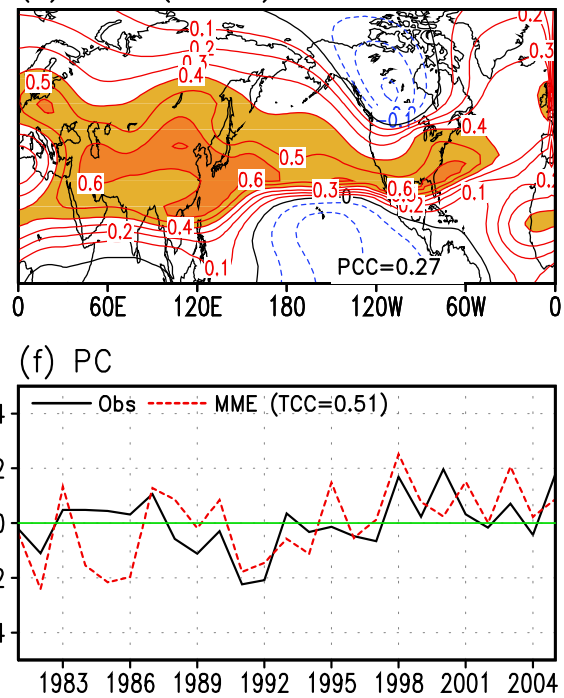

Fig. 7. Same as Fig. 4 except for DJF. 
Temporal Correlation for Seasonal SST Against PCs

(a) EOF 1
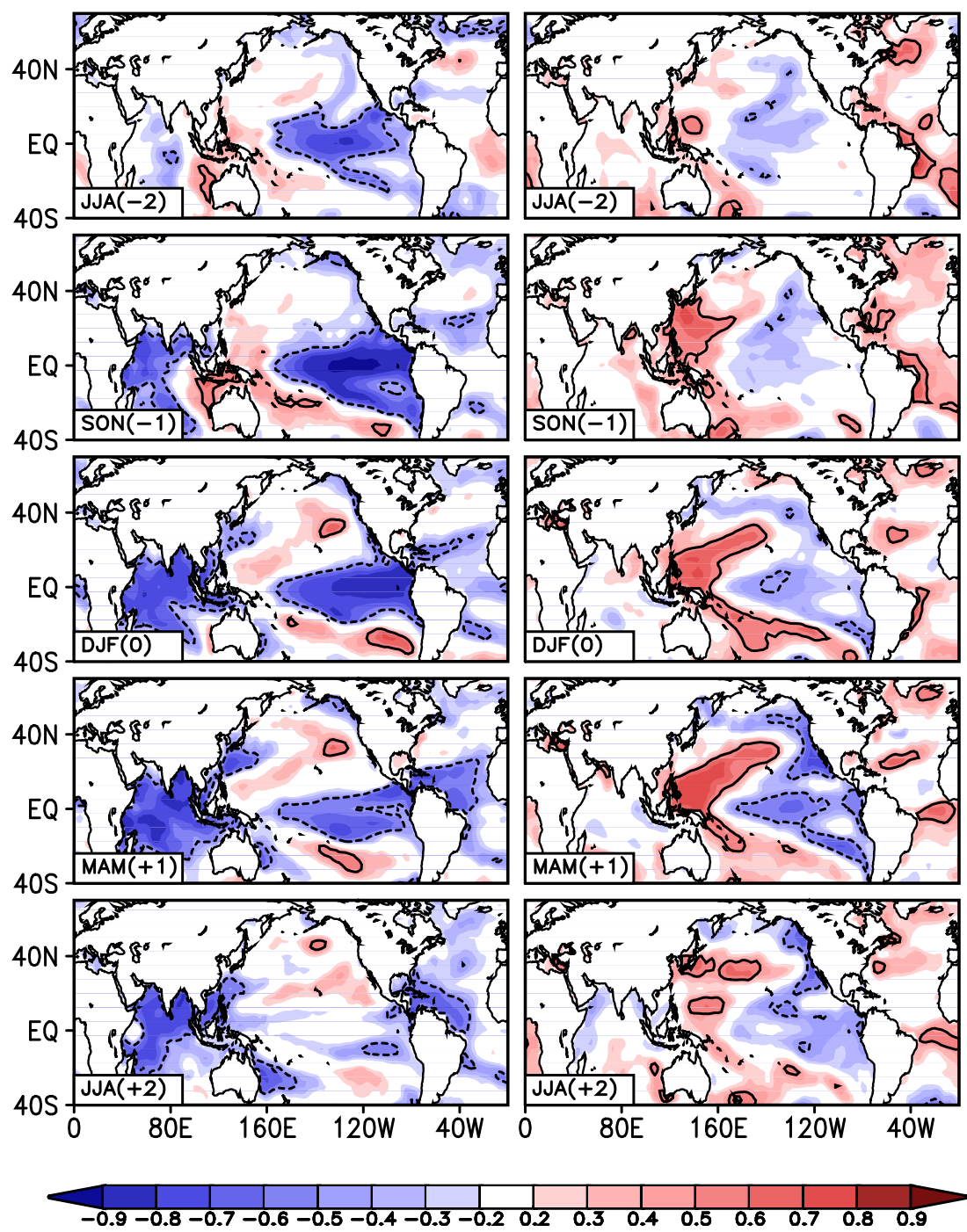

Fig. 8. Spatial patterns of the lead-lag correlation coefficients for seasonal mean SST against (a) the first PC and (b) the second PC, respectively, of DJF Z200 obtained from observations. Correlation coefficients which are statistically significant at $99 \%$ confidence level are contoured. 


\section{Predictability of seasonal-mean atmospheric circulation}

\subsection{Mean Square Error method}

For a two-tier prediction, the physical basis for the seasonal predictability lies in slowly varying lower boundary forcing, especially the anomalous SST forcing (Charney and Shukla 1981; Palmer 1993; Shukla 1998). Thus, the predictability does not depend on initial atmospheric conditions. To better extract a predictable signal, an ensemble forecast approach with different initial conditions is used to reduce the errors arising from atmospheric internal chaotic dynamics. In this system, the potential predictability is measured as the ratio between the externally forced SST signal defined by interannual ensemble mean variance and the internal noise defined by inter-ensemble variance (Shukla 1981; Roswell et al. 1995; Roswell 1998) and the upper limit of seasonal prediction correlation skill can be obtained from the signal-to-noise ratio (Kang and Shukla 2006). By definition, the approach is highly model-dependent.

To overcome the limitation of the conventional approach, Kumar et al (2007) suggested the method to optimally estimate potential predictability under a multi-model frame using the expected value of the mean square error (MSE) between the observed and the general circulation model simulated (or predicted) seasonal mean anomaly. They found that the property of MSE can be considered as an estimate of the internal variability of the observed seasonal variability because MSE equals the observed internal variability in the case of large ensembles using a dynamical model with unbiased atmospheric response. Using multi models, they found that the spatial map of the minimum value of MSE irrespective of which model it came from at each geographical location can be regarded as the best estimate for the observed internal variability. The external variance is calculated by subtracting the estimated internal variance from the observed total variance. This approach is less dependent on climate models being used but tends to underestimate the observed predictability due to models' systematic bias.

Figure 9 shows the best estimate of the internal (or noise) and external (or signal) variance of the observed Z200 anomalies in each season obtained from the minimum value of MSE in the eight coupled models. The signal-to-noise ratio ( $\rho$; SN ratio hereafter) is calculated by the ratio of the estimated internal and external variance of the observed Z200 anomalies in each season shown in Fig. 10. Significant signal variance and thus the SN ratio are observed over the entire Tropics and PNA region during DJF and MAM but over the Tropical Indian Ocean and Atlantic Ocean and some parts of Asia during JJA and SON. Note that the current estimation of the external variance and $\mathrm{SN}$ ratio is larger than that from Kumar et al. (2007)'s estimation both using AMIP simulation and DEMETER coupled hindcast indicating that the current coupled models have less systematic biases than AMIP models and DEMETER coupled models. It implies that the current estimation of potential predictability is closer to the observed true value than that of Kumar et al. (2007). There is always a room to improve the estimation using better climate model predictions with less systematic biases.

In order to compare the estimated SN ratio $(\rho)$ with the MME TCC skill, a theoretical limit of correlation coefficient $\left(R_{\text {Limit }}\right.$, Kang and Shukla 2006) is calculated using the following equation

$$
R_{\text {Limit }}=\sqrt{\frac{\rho}{\rho+1}}
$$


(a) Internal Var
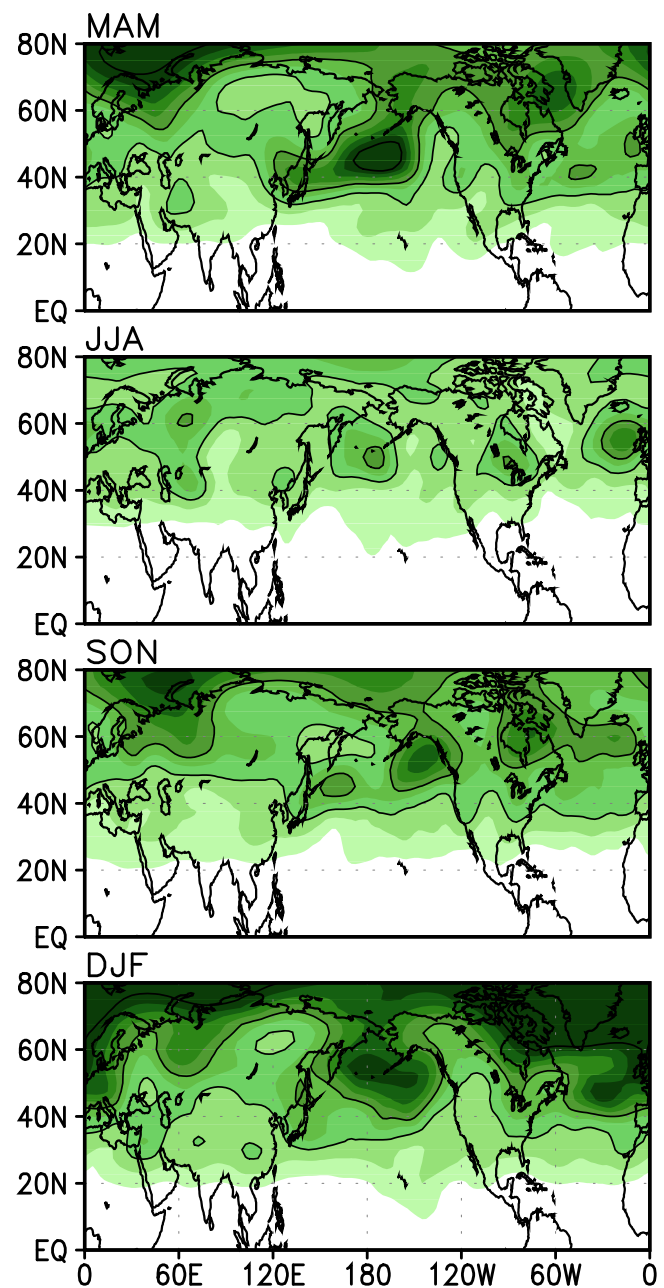

(b) External Var
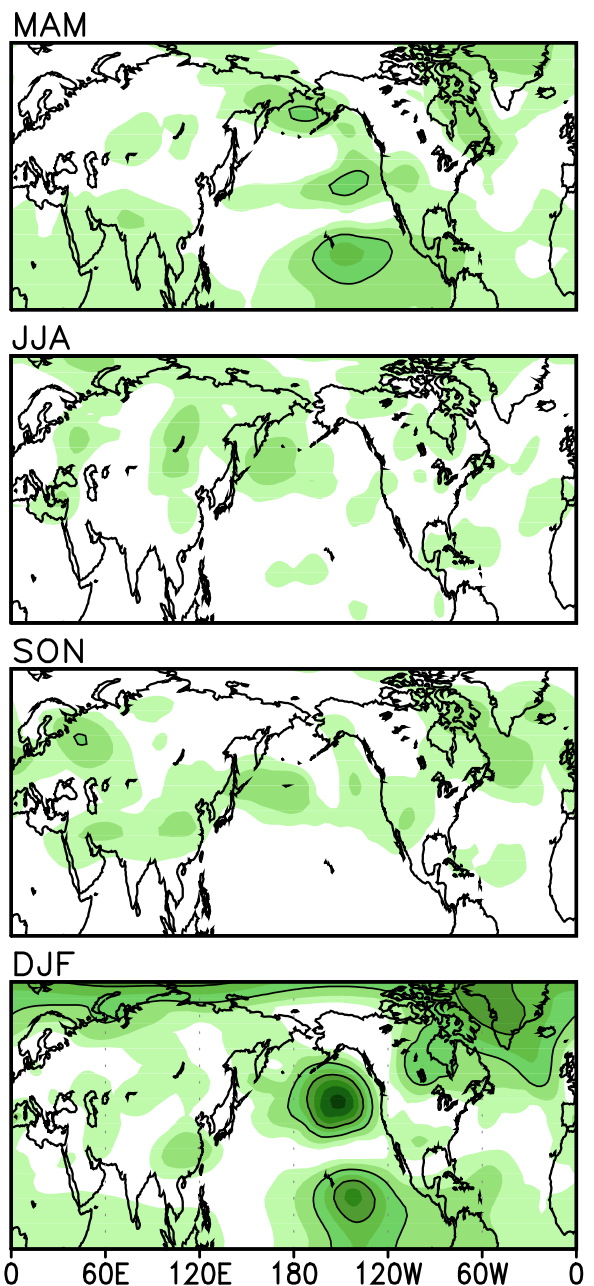

$\times 100 \mathrm{~m}^{2}$

Fig. 9. The best estimate of the (a) internal and (b) external variance of observed Z200 anomalies in each season. The unit is $\mathrm{m}^{2}$ and 1000, 2000, and $4000 \mathrm{~m}^{2}$ are contoured. 
The $R_{\text {Limit }}$ measures the intrinsic limits of the predictability due to the internal dynamics of atmospheric variability. Figure 11 indicates that the MME skill (Fig. 2) reaches the theoretical limit of TCC over the Tropics during all seasons but is less over most of the extratropical region, particularly over continents. It is interesting to note that $R_{\text {Limit }}$ is less than the MME skill over the Tropical Pacific during SON and JJA implying that climate models used in this study tend to have large systematic biases over the region during those seasons.

Signal to Noise Estimate
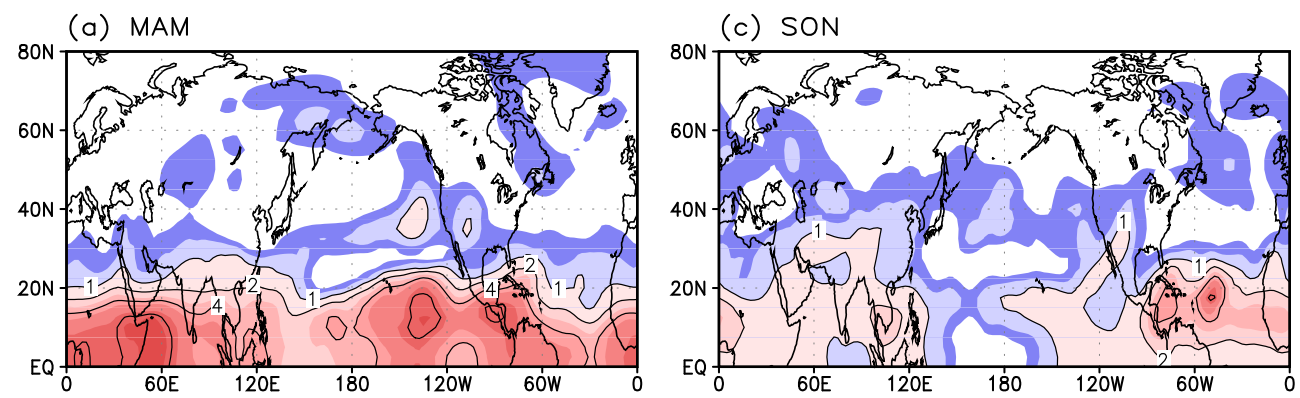

(b) JJA

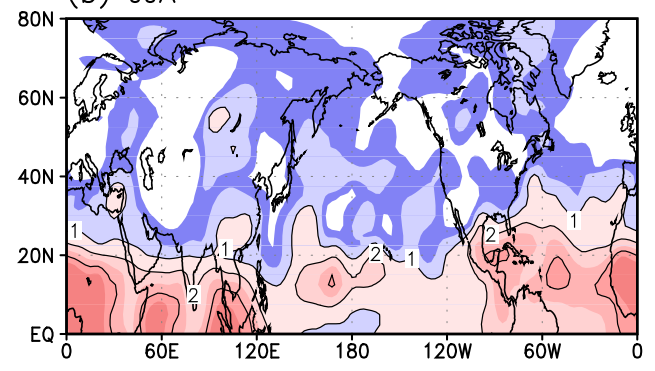

(d) DJF
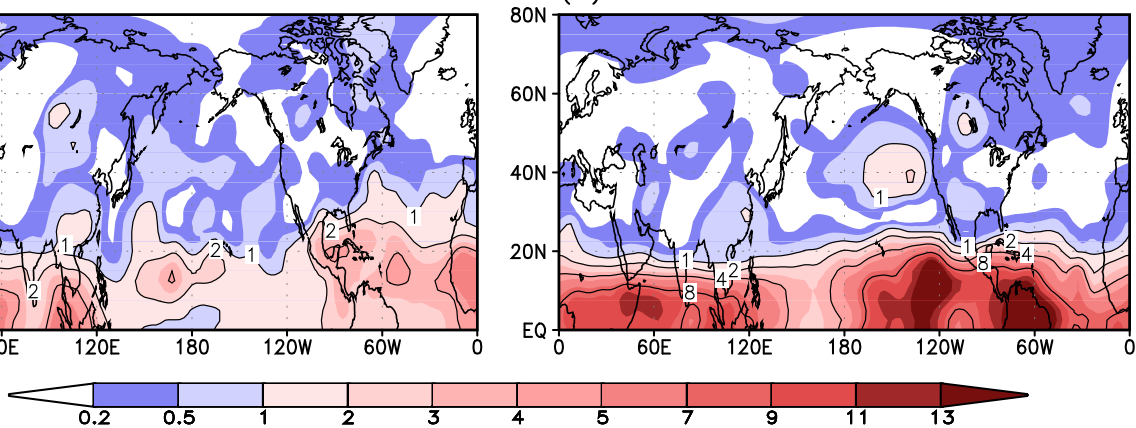

Fig. 10. The best estimate of signal-to-noise ratio for the observed Z200 anomalies in (a) MAM, (b) JJA, (c) SON, and (d) DJF computed as the ratio of external-to-internal variance. Higher ratios imply higher potential predictability. 
(a) MAM

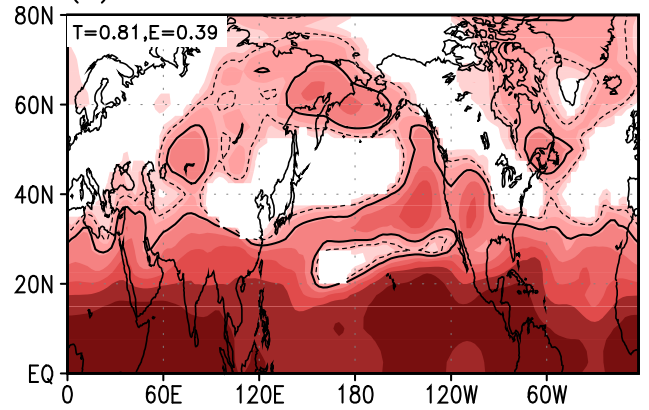

(b) JJA

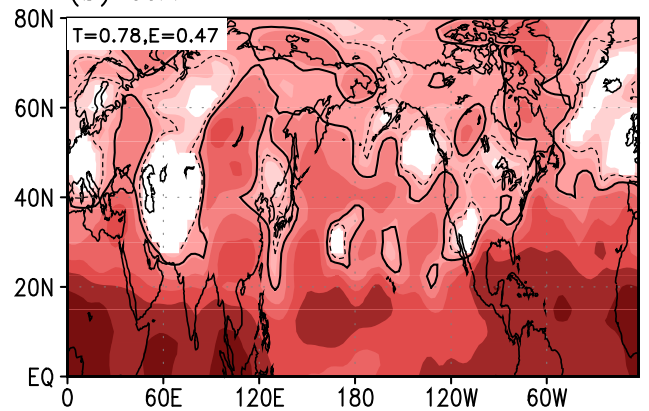

(c) SON

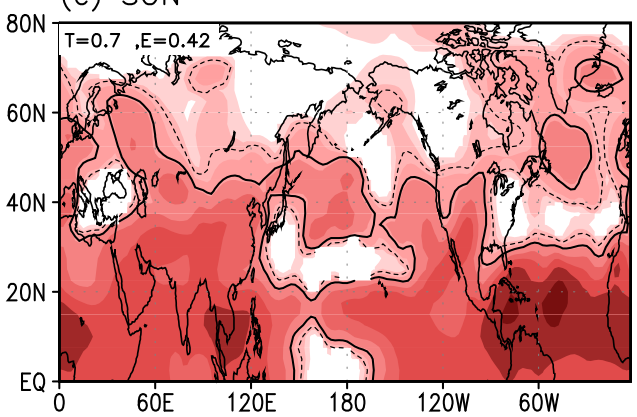

(d) DJF

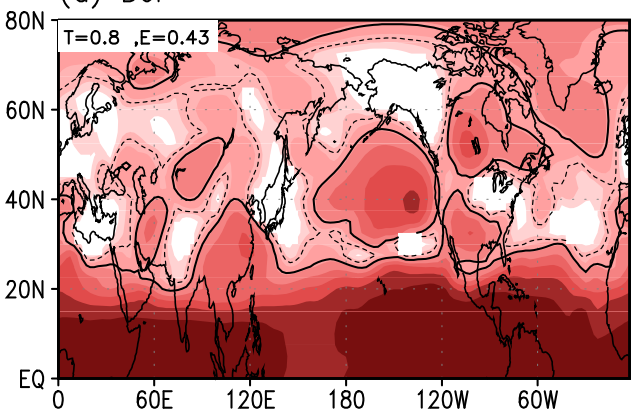

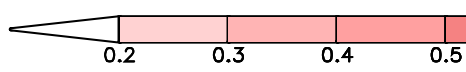

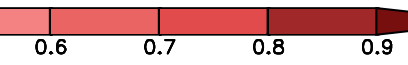

Fig. 11. Potential predictability in terms of the theoretical limit of correlation skill for Z200 in (a) MAM, (b) JJA, (c) SON, and (d) DJF using the best estimate of the internal and external variance based on MSE method. Solid (dashed) line represents statistical significance of the correlation coefficients at $95 \%(99 \%)$ confidence level. The numbers in the left upper corners indicate averaged correlation skill over the tropics $\left(\mathrm{T}, 0-360^{\circ} \mathrm{E}, \mathrm{Eq}-30^{\circ} \mathrm{N}\right)$ and extratropics $(\mathrm{E}$, $0-360^{\circ} \mathrm{E}, 30-80^{\circ} \mathrm{N}$ ) in the $\mathrm{NH}$.

\subsection{Predictable mode analysis approach}

Wang et al. (2007) and Lee et al. (2011) suggested a way to determine predictable modes and thus potential predictability using observations and the state-of-the-art climate models' predictions. There are two basic criteria for the determination. First, for observations, predictable modes should explain a large part of the total variability and be statistically separated from other higher modes. Second, the climate prediction models should be capable of predicting these major modes. According to these principles, the predictable modes are identified using percentage variance for each EOF mode in observation and the skill score of the MME prediction in terms of the combined spatial and temporal skill for each mode. 
Figure 12 shows a scatter diagram between the observed percentage variance (ordinate) and the skill score for each EOF (abscissa) mode. The first two modes are not only well separated from higher modes statistically but also predicted with high fidelity by the current coupled models' MME in MAM, JJA, and SON similar as the result of Lee et al. (2011). However, the second EOF mode in DJF is much less predictable while its first mode is the most predictable mode with the skill score of 0.96 . The low skill of the second mode is mainly attributable to the fact that the current MME has difficulty in capturing its spatial distribution over the high-latitude while it has a useful skill in capturing PC time variation (Fig. 7). Nonetheless, we consider the second mode as a predictable mode since the physical basis of the mode is understood as described in Section 3 and the MME's TCC skill for the second PC is relatively high.
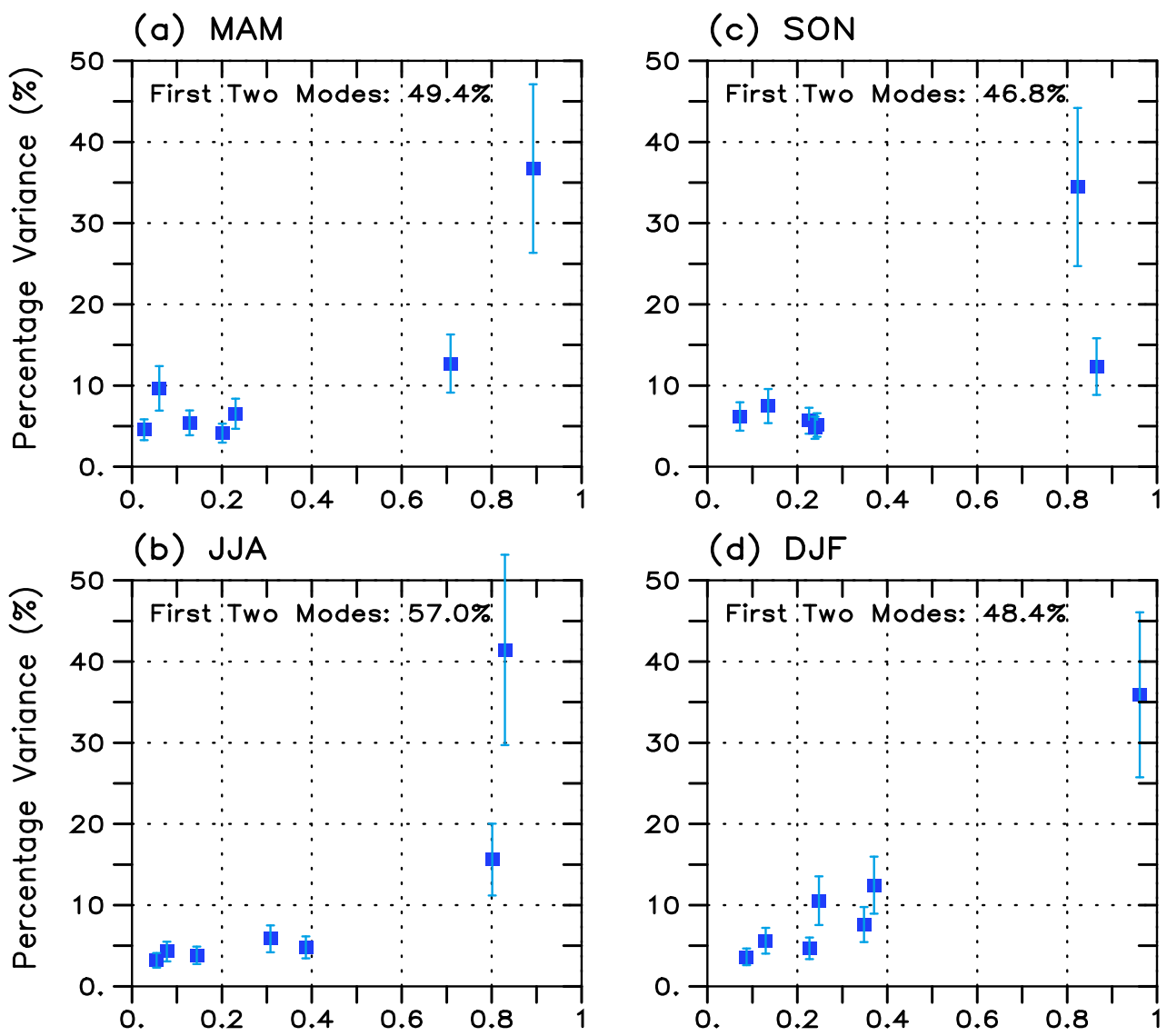

Skill Score

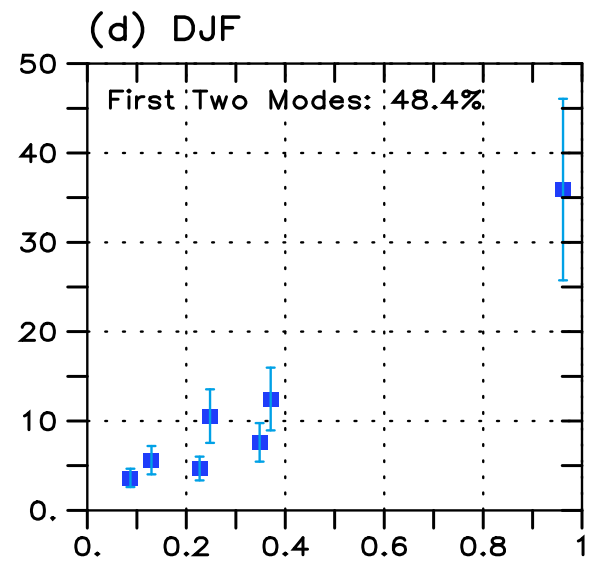

Skill Score

Fig. 12. The percentage variances that are accounted for by the observed first seven EOFs (ordinate) and the combined forecast skill score for the eigenvector and principal component for each mode (abscissa) for 200-hPa GPH in NH. The leading two modes of the observed $200-\mathrm{hPa}$ GPH in JJA capture about $57 \%$ of the total interannual variability. 
The first two modes capture about $49.4 \%, 57.0 \%, 46.8 \%$, and $48.4 \%$ of the observed total variability in MAM, JJA, SON, and DJF, respectively, over the entire $\mathrm{NH}$. Over the extratropics only, $18.8 \%(65.9 \%), 35.4 \%(82.7 \%), 18.9 \%(69.8 \%)$, and $23.2 \%(53.5 \%)$ of the observed (predicted) total variability can be explained by the first two modes in MAM, JJA, SON, and DJF, respectively (Table 3). The fractional variance can be interpreted as potential predictability from a conventional point of view. That means summer-time upper-level circulation is most predictable than the other seasons in the current approach. About $35.4 \%$ of total variability over the NH extratropics in JJA is potentially predictable but only $18.8 \%$ is predictable in MAM.

Given the assumption that the first two leading modes are more predictable and the higher modes are less predictable (Fig. 12), the total predicted as well as observed fields are decomposed into the predictable and unpredictable parts. The predictable part is reconstructed by the linear combination of the first two EOF modes and the unpredictable part is then calculated by subtracting the predictable part from the total field. The realizable potential predictability is estimated by the TCC between the observed total field and the observed predictable part in order to facilitate comparison with the MME prediction skill. Thus, it represents the achievable forecast skill if climate models can perfectly predict the observed predictable modes.

\begin{tabular}{|c|c|c|c|c|c|}
\hline \multirow{3}{*}{ Season } & \multirow{3}{*}{ MAM } & \multicolumn{2}{|c|}{ EOF1 } & \multicolumn{2}{c|}{ EOF2 } \\
\cline { 3 - 6 } & & Tropics & Extratropics & Tropics & Extratropics \\
\cline { 2 - 6 } & MME & $63.5 \%$ & $6.1 \%$ & $13.3 \%$ & $12.7 \%$ \\
\hline \multirow{3}{*}{ JJA } & Obs & $76.8 \%$ & $13.4 \%$ & $7.2 \%$ & $37.7 \%$ \\
\cline { 2 - 7 } & MME & $72.7 \%$ & $41.8 \%$ & $17.8 \%$ & $40.9 \%$ \\
\hline \multirow{2}{*}{ SON } & Obs & $58.7 \%$ & $6.9 \%$ & $13.0 \%$ & $12.0 \%$ \\
\cline { 2 - 7 } & MME & $68.6 \%$ & $46.7 \%$ & $21.6 \%$ & $23.1 \%$ \\
\hline \multirow{2}{*}{ DJF } & Obs & $60.0 \%$ & $8.0 \%$ & $9.8 \%$ & $15.2 \%$ \\
\cline { 2 - 7 } & MME & $73.7 \%$ & $22.5 \%$ & $15.0 \%$ & $31.0 \%$ \\
\hline
\end{tabular}

Table 3. Area-averaged fractional variance for the first two EOF modes over the tropics and extratropics in $\mathrm{NH}$ obtained from observation and the one-month lead MME prediction. 
Comparison between Figs. 13 and 11 indicates that potential predictability measured by the PMA method is higher over the NH tropics than that by the MSE method. Over the NH extratropics, the two methods have a comparable result in MAM and DJF but the PMA has higher (lower) predictability in JJA (SON) than the MSE. It is suggested that the two methods are complimentary to better estimate the true value of the observed predictability because they each have their own shortcoming. By definition, the two methods tend to underestimate the true value.

Potential Predictability /PMA Method
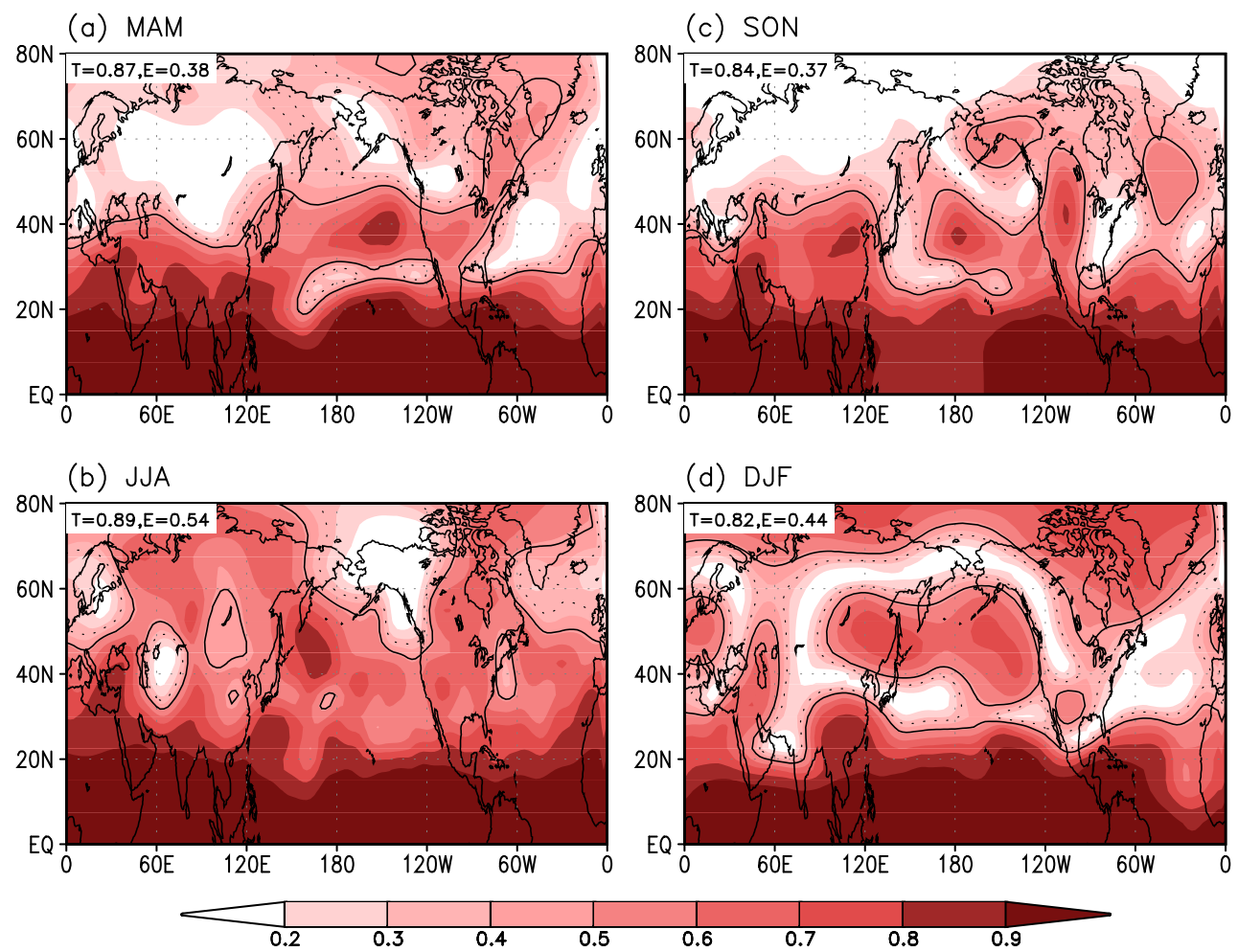

Fig. 13. Same as Fig. 12 except for potential predictability in terms of the TCC skill based on PMA method.

\section{Summary and discussion}

Using the eight fully coupled models in the CliPAS and ENSEMBELS project, prediction skill and predictability of seasonal mean upper-level atmospheric circulation are investigated over 25 years, 1981-2005. The eight coupled models' MME predicts the seasonal Z200 anomalies over the NH tropics with high fidelity, but has significantly lower skills in predicting those over the $\mathrm{NH}$ extratropics. Nonetheless, over specific geographic locations 
in the extratropics depending on season, the MME has considerable forecast skill, suggesting that predictable patterns may exist over the region of interest in each season. The MME has better skill for the Z200 anomalies over the PNA (Asian) region during MAM and DJF (JJA and SON) than the Asian (PNA) region. The area-averaged TCC skill over the NH tropics is the lowest in SON, while over the NH extratropics, it is highest in JJA.

The first two EOF modes of the Z200 anomalies in all seasons are identified as predictable leading modes for a number of reasons. First, these observed modes are statistically well separated from the higher modes and account for the large fraction of total variability; second, these modes have clear physical interpretations and their sources of variability are understood in terms of ENSO teleconnection dynamics and third, the current MME is capable of predicting the spatial structure and temporal variation of these modes with high fidelity except the second mode of the DJF Z200. Note that the low skill of the DJF second mode is mainly attributable to the fact that the current MME has difficulty in capturing its spatial distribution over high latitudes.

The first mode is associated with a typical or conventional eastern Pacific El Nino with complimentary same-sign SST anomalies occurring in Indian Ocean and Atlantic. On the other hand, the second mode seems to be associated with a central Pacific El Nino with pronounced opposite-sign SST anomalies in the western Pacific and Atlantic but little SST anomalies in the Indian Ocean. This suggest that the tropical precipitation anomalies associated with the locations of the tropical SST anomalies are critical important for determining the extratropical response.

Given the assumption that the first two leading modes can be perfectly predicted and the higher modes are noise patterns, we define the realizable potential predictability by the total fractional variances of the predictable modes. The first two modes capture about $49.4 \%$, $57.0 \%, 46.8 \%$, and $48.4 \%$ of the observed total variability in MAM, JJA, SON, and DJF, respectively, over the entire $\mathrm{NH}$, which may represent an upper limit for the forecast skill potentially obtainable using the MME prediction; thus offering an estimate of attainable potential predictability. The realizable potential predictability is calculated by the TCC between the observed total field and the observed predictable component. Potential predictability of Z200 in each season reveals that the interannual variability over particular geographic locations in the $\mathrm{NH}$ extratropics is to a large degree predictable with the first two modes, although the extratropical upper-tropospheric circulation is generally much less predictable than over the tropics.

We compare the potential predictability measured by the PMA method with that estimated by the MSE method suggested by Kumar et al. (2007). Kumar et al. (2007) demonstrated that MSE can be considered as an estimate of the internal variability of the observed seasonal variability because MSE equals the observed internal variability in the case of large ensembles using a dynamical model with unbiased atmospheric response. Using multi models, they found that the spatial map of the minimum value of MSE, irrespective of which model it came from at each geographical location, can be regarded as the best estimate for the observed internal variability. The external variance is calculated by subtracting the estimated internal variance from the observed total variance. We demonstrate that the two estimates compliment each other to better measure the true value 
of the observed predictability, taking into account their own shortcomings. It is noted that potential predictability measured by the PMA method is higher over the NH tropics than by the MSE method. Over the NH extratropics, the two methods have a comparable result in MAM and DJF, but the PMA has higher (lower) predictability in JJA (SON) than the MSE. The estimations shown here are based on the state-of-the art climate model predictions. With further improvement of climate prediction models, estimates of potential predictability will become closer to their true values.

\section{Acknowledgement}

This research was supported by APEC Climate Center and IPRC (which is in part supported by JAMSTEC, NOAA (grant No. NNX07AG53G)), and NOAA (grant No. NA09OAR4320075). Authors would like to acknowledge contributions from the CliPAS and ENSEMBLES team members. This is IPRC publication 825 and SOEST publication 8513.

\section{References}

Alessandri A., A. Borrelli, A. Navarra, A. Arribas, M. Déqué, P. Rogel, and A. Weisheimer, 2011: Evaluation of probabilistic quality and value of the ENSEMBLES multi-model seasonal forecasts: comparison with DEMETER. Mon. Wea. Rev., 139, 581-607, doi:10.1175/2010MWR3417.1.

Barnston, A. and R. E. Livezey, 1987: Classification, seasonality and persistence of lowfrequency atmospheric circulation patterns. Mon. Wea. Rev., 82, 1083-1126.

Barnston, AG, Mason SJ, Goddard L, Dewitt DG, Zebiak SE, 2003: Multimodel ensembling in seasonal climate forecasting at IRI. Bull Am Meteor Soc 84:1783-1796

Charney, J. G., J. Shukla, 1981: Predictability of monsoons. Paper presented at the Monsoon Symposium in New Delhi, India, 1977. In: Lighthill J Sir, Pearce RP (eds) Monsoon dynamics, Cambridge University Press

DelSole, T., 2004: Predictability and information theory. Part I: Measures of predictability, J. Atmos. Sci., 61, 2425-2440.

Ding, Q., and B. Wang, 2005: Circumglobal teleconnection in the Northern Hemisphere summer. J Clim 18:3483-3505

Ding, Q., B. Wang, J. M. Wallace, and G. Branstator, 2011: Tropical-extratropical teleconnections in boreal summer: observed interannual variability. J. Climate, 24, 1878-1896.

Doblas-Reyes, F. J., Déqué, M. and Piedelievre, J.-P., 2000: Multi-model spread and probabilistic forecasts in PROVOST. Q. J. R. Meteorol. Soc. 126, 2069-2087.

Folland, C., J. Knight, H. Linderholm, D. Fereday, S. Ineson, and J. Hurrell, 2009: The summer North Atlantic Oscillation: Past, Present, and Future. J. Climate, 22, 10821103.

Hagedorn R, Doblas-Reyes FJ, Palmer TN, 2005: The rationale behind the success of multimodel ensembles in seasonal forecasting - I. Basic concept. Tellus 57A: 219-233

Hoerling, M., J. W. Hurrell, and T. Xu, 2001: Tropical origins for recent north atlantic climate change. Science, 292, 90-92. 
Jia, XiaoJing, H. Lin, J.-Y. Lee, and B. Wang, 2011: Season-dependent forecast skill of the dominant atmospheric circulation patterns over the Pacific North-American region. Submitted to J. Climate.

Kang, I. S. and J. Shukla, 2006: Dynamic seasonal prediction and predictability of the monsoon. In: Wang B (ed) The Asian monsoon, Springer-Paraxis, Chichester, UK

Krishnamurti, T. N., Kishtawal, C. M., LaRow, T. E., Bachiochi, D. R., Zhang, Z. and coauthors. 1999. Improved weather and seasonal climate forecasts from multi-model superensemble. Science 285, 1548-1550.

Krishnamurti, T. N., Kishtawal, C. M., Shin, D. W. and Williford, C. E. 2000. Multi-model superensemble forecasts for weather and seasonal climate. J. Climate 13, 4196-4216.

Kumar A., B. Jha, Q. Zhang, and L. Bounoua, 2007: A new methodology for estimating the unpredictable component of seasonal atmospheric variability. J. Climate, 20, 38883901.

Lee J.-Y., B. Wang, I.-S. Kang, J. Shukla et al., 2010: How are seasonal prediction skills related to models' performance on mean state and annual cycle? Clim Dyn 35:267283

Lee, J.-Y., Wang, B., Ding, Q., Ha, K.-J., Ahn, J.-B. et al. 2011:How predictable is the Northern Hemisphere summer upper-tropospheric circulation? Clim. Dyn. 37, 1189-1203.

Lee, W.-J. et al. 2009: APEC Climate Center for climate information services, APCC 2009 Final Report (Available at http://www.apcc21.net/activities/activities03_01.php)

Leung, L.-Y., and G. R. North, 1990: Information theory and climate prediction, J. Climate, 3: 5-14.

Lorenz, E. N. 1965: A study of the predictability of a 28-variable model. Tellus, 17, 321-333

NOAA Climate Test Bed, 2006: MME White Paper (Available at http://www.cpc.noaa.gov/products/ctb/ctb-publications.shtml)

Palmer TN, Brankovic C, Richardson DS, 2000: A probability and decision-model analysis of PROBOST seasonal multi-model ensemble integrations. Q J R Meteorol Soc 126: 2013-2034

Palmer, T. N., Alessandri, A., Andersen, U. et al., 2004: Development of a European multimodel ensemble system for seasonal to interannual prediction (DEMETER). Bull. Amer. Meteor. Soc., 85, 853-872

Rowell, D. P.,1998: Assessing potential seasonal predictability with an ensemble of multidecadal GCM simulations. J. Climate 11:109-120

Shukla J et al, 2000: Dynamical seasonal prediction. Bull Am Meteorol Soc 81:2493-2606

Shukla, J., 1998: Predictability in the midst of chaos: a scientific basis for climate forecasting. Science, 282, 728-731

Trenberth, K. E., G. W. Branstator, D. Karoly, A. Kumar, N. Lau, and C. Ropelewski, 1998: Progress during toga in understanding and modeling global teleconnections associated with tropical sea surface temperature. J. Geophys. Res., 103, 12,32414,291 .

Wallace, J. M. and D. Guztler, 1981: Teleconnections in the geopotential height field during the northern hemisphere winter. Mon. Wea. Rev., 109, 784-812.

Wang, B., J.-Y., I.-S. Kang IS, J. Shukla et al.,2007: Coupled predictability of seasonal tropical precipitation. CLIVAR Exchanges, 12:17-18 
Wang, Bin, June-Yi Lee, J. Shukla, I.-S. Kang, C.-K. Park and et al., 2009: Advance and prospectus of seasonal prediction: Assessment of APCC/CliPAS 14-model ensemble retrospective seasonal prediction (1980-2004). Clim. Dyn. 33, 93-117

Weisheimer, A., F. J. Doblas-Reyes, T. N. Palmer et al., 2009: ENSEMBLES:A new multimodel ensemble for seasonal-to-annual predictions-Skill and progress beyond DEMETER in forecasting tropical Pacific SSTs. Geophys. Res Lett, 36, L21711. 


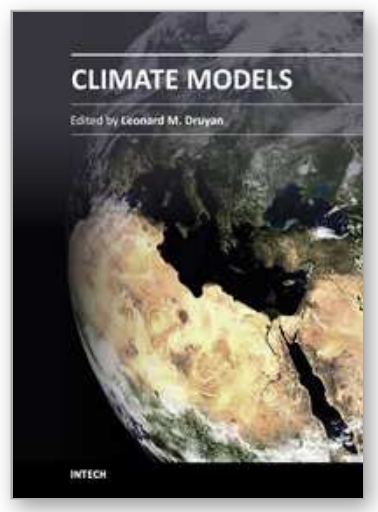

\author{
Climate Models \\ Edited by Dr. Leonard Druyan
}

ISBN 978-953-51-0135-2

Hard cover, 336 pages

Publisher InTech

Published online 02, March, 2012

Published in print edition March, 2012

Climate Models offers a sampling of cutting edge research contributed by an international roster of scientists. The studies strive to improve our understanding of the physical environment for life on this planet. Each of the 14 essays presents a description of recent advances in methodologies for computer-based simulation of environmental variability. Subjects range from planetary-scale phenomena to regional ecology, from impacts of air pollution to the factors influencing floods and heat waves. The discerning reader will be rewarded with new insights concerning modern techniques for the investigation of the natural world.

\title{
How to reference
}

In order to correctly reference this scholarly work, feel free to copy and paste the following:

June-Yi Lee and Bin Wang (2012). Seasonal Climate Prediction and Predictability of Atmospheric Circulation, Climate Models, Dr. Leonard Druyan (Ed.), ISBN: 978-953-51-0135-2, InTech, Available from:

http://www.intechopen.com/books/climate-models/seasonal-climate-predictability-of-atmospheric-circulation

\section{INTECH}

open science | open minds

\section{InTech Europe}

University Campus STeP Ri

Slavka Krautzeka 83/A

51000 Rijeka, Croatia

Phone: +385 (51) 770447

Fax: +385 (51) 686166

www.intechopen.com

\section{InTech China}

Unit 405, Office Block, Hotel Equatorial Shanghai

No.65, Yan An Road (West), Shanghai, 200040, China 中国上海市延安西路65号上海国际贵都大饭店办公楼 405 单元

Phone: +86-21-62489820

Fax: $+86-21-62489821$ 
(C) 2012 The Author(s). Licensee IntechOpen. This is an open access article distributed under the terms of the Creative Commons Attribution 3.0 License, which permits unrestricted use, distribution, and reproduction in any medium, provided the original work is properly cited. 